Studia Rossica Gedanensia, 5/2018, 66-74, ISSN 2392-3644 (online), ISSN 2449-6715 (print)

https://doi.org/10.26881/srg.2018.5.05

\title{
ИНТЕРНАЦИОНАЛЬНЫЕ ЭЛЕМЕНТЫ В СЛОВООБРАЗОВАНИИ РУССКОГО И ЛАТЫШСКОГО ЯЗЫКОВ
}

\author{
ВЛАДИСЛАВ ЗАМАЛЬДИНОВ \\ им. Н.И. Лобачевского \\ Кафедра современного русского языка и общего языкознания \\ ул. Большая Покровская, д. 37, 603000, г. Нижний Новгород, Россия. \\ e-mail: zvlad-nn@yandex.ru \\ ORCID: https://orcid.org/0000-0003-4513-3571 \\ ДАИКИ ХОРИГУТИ \\ Университет Иватэ (Япония) \\ Morioka, Ueda 3-18-8, Iwate, 020-8550, Japan \\ e-mail: sirdspuksti@gmail.com \\ ORCID: https://orcid.org/0000-0003-0724-6209 \\ (получено 23.08.2018; принято 12.09.2018)
}

Национальный исследовательский Нижегородский государственный университет

\section{Abstract \\ International elements in the word-formation of Russian and Latvian languages}

The article examines international elements in the word-formation processes of the Russian and Latvian languages. The features of the structure and semantics of innovations are analyzed. Moreover, the most productive conventional ways of word formation are revealed. 


\section{Key words}

International elements, word-forming neologisms, media, Russian, Latvian.

\section{Резюме}

В статье рассматриваются интернациональные элементы в словопроизводстве русского и латышского языков. Анализируются особенности структуры и семантики новообразований, выявляются наиболее продуктивные узуальные способы словообразования.

\section{Ключевые слова}

Интернациональные элементы, словообразовательные неологизмы, СМИ, русский язык, латышский язык.

\section{Предварительные замечания}

Деривационная система славянских и балтийских языков обладает высокой продуктивностью, и аффиксы непрерывно расширяют и обогащают её новыми словообразовательными элементами.

На рубеже XX-XXI вв. как в русском, так и в латышском языке происходит активизация процесса создания новых номинаций, что связано с изменениями в общественно-социальной и политической сфере Российской Федерации и Латвии.

В производстве словообразовательных неологизмов (новообразований) широко используются морфемы иностранного происхождения, что обусловлено тенденцией к интернационализации в современном русском и латышском языках. По утверждению Л. П. Крысина, «интернациональные слова и термины в каждом развитом современном языке составляют значительный слой лексики. Постоянное увеличение этого слоя свидетельствует о возрастающей тенденции к созданию своего рода международного лексического фонда, облегчающего взаимопонимание между представителями разных народов и культур» (Крысин, 2007, с. 124).

Интернациональные элементы в каждом языке проявляют преимущественно один и тот же семантический потенциал, что соответствует их природе. По сравнению с исконными словообразовательными аффиксами, интернациональные элементы выделяются высшей степенью семантической прозрачности и регулярности, что способствует производству неологизмов по аналогии с другими современными языками мира, а это способствует расширению интернационализации в целом.

Интернациональные элементы порой не описываются в грамматиках (Vulāne, 2013, с. 212-249) и по сравнению с исконными словообразовательными элементами занимают периферийное место. Однако они, присоединяясь к основе вне 
зависимости от её происхождения, несомненно, причастны к пополнению современного лексикона, особенно именного.

В качестве источников материала были использованы русские и латышские тексты СМИ. Все примеры представляют собой продукты словообразования новейшего времени, т.е. на рубеже XX и XXI вв.

\section{Интернациональные словообразовательные элементы}

Отличительной особенностью современного словообразования является создание инноваций с иноязычными префиксами. Так, продуктивной в русском языке является пейоративная приставка $\boldsymbol{a} \boldsymbol{н} \boldsymbol{u} \boldsymbol{u}$ - с семантикой 'противоположность чему-либо; направленность против чего-либо, в ответ на что-либо' (Лопатин, Улуханов, 2016, с. 44): Художник-провокатор Бэнкси построил антиДиснейленд - самую мрачную достопримечательность Англии («Версия в Нижнем Новгороде», 21.08.2015); А если Украина - это не анти-Россия, то иель ее независимости оказывается под большим вопросом («Аргументы и факты», 24.08.2017); У депутатов произошло резкое обострение анти-США риторики («Московская правда», 23.10.2017); Главное, чтобы мы не стали устраивать у себя, в Российской Федерации, анти-Запад («Взгляд», 13.04.2018). Особая словообразовательная семантика возникает у новых номинаций с префиксом aнmu- на базе одушевлённых собственных имен: Но другой - это Богоматерь, «новая Ева», анти-Ева: с архангелова возгласа "радуйся!» (ave, то есть Еvа в зеркальном отображении) начинается новая жизнь всего человечества («Коммерсантъ Weekend», 22.09.2017); Библиотека - это своеобразный «анти-Трамп» - мир, основанньй на доброжелательном любопьтстве («Коммерсантъ Weеkend», 15.12.2017); Новое Средневековье, Анти-Эдип и дедуика Спилберг - вот это мэшап, подобного которому нет места ни во вселенной «Марвел», ни в мире комиксов DC! («Коммерсантъ Weekend», 30.03.2018). Как видно из примеров, в качестве производящих существительных могут выступать имена библейских персонажей, политиков, древнегреческих героев. Кроме того, в русском языке префикс анти- активен и при образовании потенциальных имен прилагательных: Антимедведевский фильм о пятидневной войне с Грузией весьма симптоматичен. Потеря Медведевым президентского поста провоцирует его противников на сведение старых счётов («Полит.ру», 08.08.2012); После этого на Носкова вылили ушаты грязи из бердниковского «идеологического блока». Когда Иван Николаевич прибыл в Нижний Новгород и стал смотрячим за «старой администрацией города», а его имя начали упоминать в интернете, сразу мошно потекла по трубам антиносковская пропаганда со ссылками на Иркутск («Заноза», 17.05.2018). Таким образом, в современном русском языке препози-

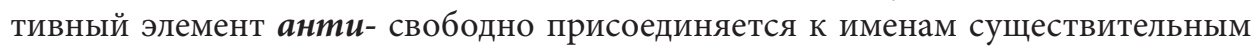
и прилагательным.

Латышский материал показывает подобную картину: Pirms referenduma valdība bija izvērsusi masīvu antibēgḷ kampan̦u, kas dal̦ai, iespējams, jau pieriebās. 'До референдума власти развернули массовую кампанию антибеженцев, кото- 


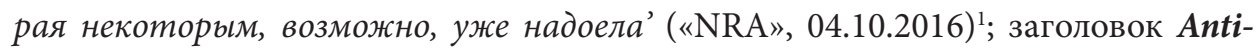
saskaņas koalīcija nostiprināta. 'Коалиция анти-Согласия укреплена' (NRA», 07.02.2017)2; Tikmēr Hamburgas iedzìvotāji aizvien skal̦āk kritizē varasiestādes un policiju, kas trīs naktis pēc kārtas ḷāva gandrīz netraucèt pilsētas ielās ālēties anarhistiem, antiglobālistiem, antifašistiem un citām huligānu grupām. 'Между тем жители Гамбурга все громче критикуют власти и полицию, которые в течение трёх последовательных ночей практически не препятствовали анархистам, антиглобалистам, антифашистам и другим хулиганским группам на улииах города' («NRA», 10.07.2017); Vai ir viegli nodalit: antiputiniskais un proputiniskais? 'Легко ли разделить: антипутинский и пропутинский? («SestDiena», 18.05.2018).

Если в русском языке продуктивно образование имен прилагательных, то в латышском языке характерны производные, которые представляют собой обособленную форму родительного падежа и функционируют как определение. Vakar pirmo reizi kopš oktobra Drēzdenē nenotika tradicionālā demonstrācija pret reliğiozo fanātismu, kas nereti tiek dēvēta arī par antiislāmistu demonstrāciju. 'Вчера впервые с октября в Дрездене не состоялась традииионная демонстрация против религиозного фанатизма, которая нередко называется также антиисламистской демонстрацией (буквально - демонстрацией антиисламистов)' («NRA», 20.01.2015).

Кроме того, если в русском языке во многих случаях употребляется дефис при производных словах с интернациональными префиксами, то в латышском языке при них характерно слитное написание. Хотя порой можно наблюдать колебания: дефисное написание, возможно, под влиянием английского и русского языков (anti-Maidan 'aнmu-Майдан', anti-Tramps 'aнmu-Трамn'), и намного реже - раздельное написание (anti Merkele 'aнmи Меркель').

В современных деривационных процессах активизировались размерно-оценочные префиксы супер-, мега- с семантикой повышенного качества или усиленного действия: Самим Кустурицей о группе снят документальныц бильм под названием «Истории супер-восемь» («Версия в Нижнем Новгороде», 15.05.2017); Сегодня из вас готовы сделать супер-любовнииу, невероятного пикапера, светскую львииу, лучшую в мире жену и т.д. («Аргументы и факты», 27.02.2018); заголовок Мега-коррупиия или сор из ОНФ-избы? («Нижний сейчас», 21.01.2016); Земля опять переживает вторжение монстров, а им противостоят новые мега-егеря («Аргументы и факты», 28.02.2018). Необходимо отметить, что сочетаемость с собственными именами существительными свидетельствует о расширении синтагматических возможностей префиксов супери мега-: заголовок Супер-Козак. Какие полномочия сосредоточил в своих руках новый глава Минрегионразвития («Версия в Нижнем Новгороде», 08.05.2018); В Китае снесли 36-метровую статую золотого «мега-Мао» («Версия в Нижнем Новгороде», 08.01.2016).

В латышском языке также широко используются префиксы super- и mega-. Они присоединяются к основе для выражения масштабности и субъективной

\footnotetext{
1 Перевод с латышского языка на русский выполнен авторами - прим. ред.

2 Saskaņa 'Согласие' - политическая партия.
} 
оценки: Var akcentēt divas svarīgas īpatnības, kas raksturo šo superkrīzi. 'Mожно акиентировать две важные особенности, которые характеризуют этот супер-кризис' («Rīgas Balss», 19.03.2009); Stabilitāte kooperatīvam ir l̦oti svarīga, nereti to grauj visādi nepārdomāti superizrāvieni, kuriem diemžēl visai bieži seko superkritieni. 'Стабильность кооператива очень важна, нередко его подрывают всякие необдуманные супер-рывки, которые, к сожалению, очень часто следуют за супер-падениями' («Latvijas Avīze», 01.02.2016); Atklāti sakot, es biju piemirsusi, ka lìdzās megatraǵēdijai un megamīlestībai Titānikā ir arī kailskati, precīzāk, nu jau l̦oti puritāniskā aina, kurā aktrise pozē savam portretam. 'Откровенно говоря, я забыла, что, помимо мегатрагедии и мегалюбви, в "Титанике» есть ещуе страстные сиень, точнее, уж очень пуританская сцена, где актриса позирует для своего nopmpema' («Diena», 04.04.2012); Pekina uzskata Irānu par svarīgu partneri arī megaprojekta Viena josla, viens cel̦š ietvaros. 'Пекин считает Иран важным партнёром также в рамках мегапроекта «Один пояс и один путь»' («Diena», 18.06.2018).

Для обоих языков характерны приставки квази-, псевдо- с семантикой ложности, несоответствия реальности. Данные префиксы активно участвуют в образовании существительных в современном русском языке: «Квази» в экономике - это квазиприбыли и чистые убылтки («Московский комсомолец», 05.07.2017); Лавров рассказал о намерении США создать «квазигосударство» в Сирии («Аргументы и факты», 16.02.2018); США вновь, как и в случае с Иерусалимом, останутся в квази-изоляции («Аргументы и факты», 08.05.2018). Нередко имена собственные выступают в качестве производящей базы для новообразований с префиксами квази-, псевдо-: Это, с одной сторонь, вариант с кандидатомженшиной, а с другой - такая попьтка найти некоего квази-Прохорова, как было в 2012 году («Полит.ру», 01.09.2017); Председатель Временного правительства предстает карикатурным псевдо-Бонапартом, не способным ни на что серьезное («Полит.ру», 15.04.2017); Утверждают, что всего Рорих успел нарисовать и продать более сорока копий псевдо-Сибилл, многие из которых до сих пор не найдены («Полит.ру», 19.11.2017); Например, псевдо-Юлия сообщает, что находится в США, ее последний твит датируется 1 мая («Московский комсомолец», 02.05.2018). Таким образом, «обилие новообразований с данными префиксами в современных российских СМИ отражает неприятие ситуации смены ценностных ориентиров в стране» (Радбиль, Рацибурская, 2017, с. 36).

В латышском языке приставки $\boldsymbol{k v a z i -}$ и pseido- также придают значения ложности и несоответствия: Тас̌и neviena no jaunajām valstīm nevar saukties par īsto demokrātiju. Tās ir kvazidemokrātijas jeb pseidodemokrätijas. 'Всё-таки ни одно из новых государств не может называться настоящей демократией. Это квазидемократии или псевдодемократии' («Latvijas Vēstnesis», 20.06.2008); Rietumos jau labu laiku publiskajā telpā dominē jaunā cilvēktiesību un brīvību kvazireliğija, kuras centrā ir nevis Dievs, bet cilvēks, uz kura pamata arī veidojas 21. gadsimta ES. 'Ha зanade уже долгое время в публичном пространстве доминирует новая квазирелигия прав человека и свобод, в иентре которой не Бог, а человек, на основе которого и складывается ЕС 21-ого века' ("NRA», 08.02.2017); Savukārt “Latvijas Sargs” apgalvo, ka avize ved polemiku Latvijas valsts interesēs, cenšoties noraut masku pseidopatriotam un pseidovalstsviram. 'А «Латвияс Саргс» утверждает, что газета ведет 
полемику в интересах татвийского государства, стараясь оторвать маску у псевдопатриота и псевдогосдеятеля' («Kursas laiks», 22.03.2018).

Префикс экс- вносит значение 'бывший ранее тем, кто (что) назван(о) мотивирующим существительным' (Лопатин, Улуханов, 2016, с. 239): Экс-тренер «МЮ»Алекс Фергюсон госпитализирован в тяжелом состоянии («Аргументы и факты», 05.05.2018); Российская бигуристка, победительница юношеской Олимпиады-2016 Полина Цурская заявила о прекращении сотрудничества с тренером Этери Тутберидзе, экс-наставником Евгении Медведевой («Взгляд», 07.05.2018); Военная прокуратура Одесского гарнизона Южного региона Украинь подозревает экс-рулевого-сигнальщика учебного катера Академии ВМС им. Нахимова в дезертирстве («Московский комсомолец», 08.05.2018); Вместо того, чтобы привлечь к ответственности нелегальных продавцов алкоголя, экс-полицейский потребовал у продави,ов взятку в размере 7000 рублей за несоставление протокола об административном правонарушении («Московский комсомолец», 09.05.2018). По мнению исследователей, «префикс экс- отражает динамику общественно-политической жизни, обозначая лиц, утративших свой статус. Несмотря на то что производящие слова оценочно-нейтральны, в значении новообразований под влиянием контекста возникает отрицательная оценочность» (Рацибурская, Замальдинов, 2017, с. 37).

Префикс eks- в латышском языке тоже функционирует активно: Pēdējā partija, kas pārvarēs 5 \% barjeru, būs ekspremjeres un ekscietumnieces Jülijas Timošenko Batkivščina, kura iepriekšējās vēlēšanās ieguva trīsreiz vairāk par pašreizējiem sešem procentiem. 'Последняя партия, которая преодолеет барьер в 5 \%, будет «Батькивщина» экс-премьера и экс-тюремниць Юлии Тимошенко, которая в предьдущих выборах получила в три раза больше нынешних шести процентов' («NRA», 29.10.2014). Следует отметить, что новообразования с префиксом eksмогут быть усилительно-оценочным средством: Melo prezidents, eksprezidents, ekseksprezidents, premjers, aizsardzības ministrs, citi ministri, Ārlietu ministrija ar ministru priekšgalā, deputāti, arī eirodeputāti. 'Врут президент, экс-президент, эксэкс-президент, премьер, министр обороны, другие министрь, министерство иностранньх дел во главе министра, депутать, ещзе евродепутать' («Pietiek. com», 18.04.2018).

Как видно из примеров, префиксы экс-/eks- присоединяются к существительным, называющим лица. Однако присоединение их к существительным, называющим место и учреждение, пусть нечастотное, также не исключено: Его команда тренируется в Подмосковье, на экс-базе "Сатурна» в Кратово, поэтому выцелить время для поездки в Махачкалу для Расима не мудрено («Труд», 01.07.2011); Первоначально двухэтажное здание в 1960-е надстроили еще на этаж, но свой элитный статус экс-гимназия потеряла, похоже, уже навсегда («Ковровские вести», 31.10.2017); В случае если Резекне лишится статуса города республиканского подчинения, на карте может появиться новое самоуправление - объединенные экс-город Резекне и Резекненский край («Латвийские рейтинги», 13.01.2018); Iespējams, ka banku pašlikvidācijas procesā tās mēéginās saglabāties zem mazāk pretenciozām un lètākām izkārtnēm. Eksbankas varētu papildināt noguldījumu pārvaldī̌̆anas sabiedrību [...] pulciņus. 'Возможно, что в проиессе самоликвидаи,ии 
банков они будут стараться оставаться под менее привлекательными и более дешевыми знаками. Экс-банки могли бы дополнить группу депозитных компаний’ («NRA», 19.03.2018).

Значительным словообразовательным потенциалом в русском и латышском языках обладают интернациональные суффиксы и суффиксоиды. Так, производные существительные с английским суффиксом -инг приобретают семантику 'действие, объектом которого является то, что названо мотивирующим словом' (Лопатин, Улуханов, 2016, с. 388): «Бийск - пельменная столииа Алтая», - под таким девизом в ноябре впервые пройдет чемпионат по спортивному пельменингу. Именно так решили назвать организаторы команднье соревнования по ручной лепке пельменей на скорость («Новости Горного Алтая», 07.10.2014); заголовок Шашлькингу - быть! Короли мангала зажгли, запекли, накормили («Проект 111», 08.06.2016). В качестве производящих слов используются и имена собственные: Понятно, почему на просторах глобального Интернета уже появилось новое словечко - «псакинг». Так говорят, когда человек, не разобравшись, делает безапелляиионные заявления, при этом путая факты, без последующих извинений («INTERPOLIT», 03.06.2014); заголовок «Трампинг» XXI века. Игра на публику или поиск реальных компромиссов? («Вместе-РФ», 22.06.2018). Анализ фактического материала показывает, что англоязычная морфема набирает активность в современном русском языке. Словообразовательные неологизмы с суффиксом -инг обладают ярко выраженной экспрессивностью, являются средством создания иронического эффекта.

В латышском языке суффикс -ing- не обладает такой словообразовательной активностью, как в русском языке. Большинство слов являются прямыми заимствованиями из английского языка (dopings 'допинг', kempings 'кемпинг', šopings 'шоппинг'). Одни слова на -ing- обозначают относительно новые понятия и явления (brendings ‘брендинг', koučings ‘коучинг', märketings 'маркетинг’), другие существуют параллельно исконным словам, обозначающим одни и те же понятия (strečings 'стречинг', dresings 'салатный соус'). Несмотря на то, что в публичном пространстве и современной образовательной системе английский язык является главным иностранным языком и наиболее влиятельным в плане языковых контактов (Bušs, 2013, p. 142), на данный момент выделение -ing- как суффикса составляет определенную трудность. Следует отметить, что присоединение суффикса к исконной основе не наблюдается.

В ходе деривационных процессов образуются существительные с продуктивным суффиксоидом -гейт со значением 'политический скандал': заголовок Желающий расследовать «Пиица-гейт» вокруг Клинтон открыл огонь в пициерии в Вашингтоне («Ведомости», 05.12.2016); заголовок Две главных причины мундиальгейта («Syg.ma», 28.06.2018). Следует отметить, что в русском языке новообразования с суффиксоидом -гейт могут быть созданы на базе антропонимов: заголовок Хилларигейт покруче Уотергейта - Трамn («Axar.az», 30.10.2016); заголовок Макронгейт: хакеры раскопали офшорные счета Макрона и вещество на «к» («Вести.Ru», 06.05.2017); В то же время собственного мужа - наследника престола - «народная приниесса» изображала в самом черном свете. С ее подачи разгорались чудовищные скандаль, самым неприятным из которьх 
стал «Камилла-гейт» («Взгляд», 07.08.2017). Кроме того, антропонимы могут переходить в разряд имен нарицательных: Или же мы наблюдаем более сложные игры, учитывая, что практически одновременно с событиями в Кемерово случился «улюкаевгейт»? («Тайга. инфо», 16.11.2016). Таким образом, с помощью новообразований с суффиксоидом -гейт журналисты оказывают эмоциональное воздействие на адресата, распространяют негативную информацию.

Одним из важнейших событий в истории латвийской политики является Jūrmalgeita - скандал, связанный со взяткой в размере 20000 евро накануне выборов мэра города Юрмала в 2005 году: Notikums, kas ieguva nosaukumu «Jürmalgeita», ir viens no lielākajiem pirmajiem politiskās korupcijas skandāliem Latvijas vēsturē. 'Событие, названное «Юрмалгейт», является одним из крупнейших скандалов политической коррупиии в истории Латвии' («Latvijas Avīze», 04.12.2017). По модели данного производного создан ряд новообразований (tautologia), связанных с конкретными политическими деятелями: Uz tā fona, protams, savu lomu spèlēs jaunā prezidenta ievēlēšana, un citi notikumi, kas saistīti ar korupcijas skandāliem - Lemberggeita un tamlìdzīgi. 'На этом фоне, конечно, свою роль будет играть назначение нового президента и другие собьтия, которье связаны с коррупиионными скандалами - Лемберггейт и тому подобное' («NRA», 03.07.2007); Un Latvijā ir vēl visādas šlesergeitas, par kurām sabiedrība nekā nezina. 'И в Латвии есть ещзе всякие илесергейты, о которых общество ничего не знает' ("Druva», 03.12.2011). В отличие от предыдущих примеров, элемент -geit- не может соединяться со словосочетанием, скажем, «Рижская дума». Поэтому здесь образуется аналитическая лексема, где элемент употребляется в качестве самостоятельного слова: Jūrmalgeita - rezultātu nav! Rīgas domes geita - rezultātu nav! 'Юрмалгейт - результатов нет! Гейт Рижской думьь - результатов нет!' («Diena», 22.04.2010). В обществе сложилось представление о передаваемой суффиксоидом семантике, о чем свидетельствует употребление суффиксоида как самостоятельной лексической единицы: Sabiedrībai patīk dažādas “geitas”, dažādi skandāli. 'Обществу нравятся разные «гейтыı», разные скандаль' («Latvijas Avīze», 19.09.2007).

Следует отметить активный процесс деонимизации в русском и латышском языках. Имя собственное при помощи интернациональных элементов и других словообразовательных средств может переходить в имя нарицательное. Разного рода имена собственные мотивируют производные слова, которые наглядно отражают отношение говорящего к современным реалиям.

\section{Выводы}

Анализ интернациональных элементов в словопроизводстве русского и латышского языков показал, что большинство новых номинаций в обоих языках создано в соответствии с традиционными словообразовательными типами. Так, по нашим наблюдениям, заимствованные приставки (aнmu-/anti-, cynep-/ super-, мега-/mega-, квази-/kvazi-, nсевдо-/pseido-, экс-/eks-), суффиксы (-инг/ing-), суффиксоиды (-гейm/ -geit-) характерны не только для российских, но 
и латвийских медиатекстов. Рассматриваемые морфемы являются интернациональными, восходящими к латинскому и греческому языкам, за исключением суффиксов английского происхождения -uнг/-ing- и -zeŭm/-geit-. Поэтому в целом словообразовательные элементы в обоих языках имеют общую семантику.

Кроме того, активное использование в обоих языках словообразовательных неологизмов, отличающихся экспрессивностью и оценочностью, обеспечивает эффективность речевого воздействия.

\section{Библиография}

Крысин, Л.П. (2007). Современный русский язык. Лексическая семантика. Лексикология. Фразеология. Лексикография. Москва: Академия.

Лопатин, В. В., Улуханов, И. С. (2016). Словарь словообразовательных аффиксов современного русского языка. Москва: Издательский центр «Азбуковник».

Радбиль, Т. Б., Рацибурская, Л. В. (2017). Словообразовательные инновации на базе заимствованных элементов в современном русском языке: лингвокультурологический аспект. Мир русского слова, № 2, с. 33-39.

Рацибурская, Л. В., Замальдинов, В. Е. (2017). Особенности новообразований с экспрессивно-оценочной семантикой в региональной нижегородской прессе. Вестник Московского государственного областного университета. Серия: Русская филология, № 4, с. 34-41.

Bušs, O. (2013). Latviešu valodas leksika. B: Veisbergs, А. (ред.). Latviešu valoda. Rīga: LU Akadēmiskais apgāds, c. 133-156.

Vulāne, A. (2013). Vārddarināšana. B: Auziņa, I. [et al.] (ред.). Latviešu valodas gramatika. Rīga: LU Latviešu valodas institūts, c. 190-299. 